\title{
Two Comments on "Governance Indicators: Where Are We, Where Should We Be Going?" by Daniel Kaufmann and Aart Kraay ${ }^{1}$
}

The following comments by Shantayanan Devarajan and Simon Johnson provide two perspectives on indicators in general and the World Governance Indicators in particular.

Shantayanan Devarajan

The World Bank Research Observer publishes balanced surveys of the literature. When the authors of a survey are also the proponents of one of the major indicators being surveyed, it invites comments to ensure that balance is maintained.

Kaufmann and Kraay provide a useful taxonomy of governance indicators, distinguishing between those measuring "rules on the books" and "rules on the ground" and those reflecting the views of experts and the results of surveys. While providing a balanced overview of the pros and cons of different methods, they make a strong case in favor of measuring rules on the ground based on an aggregated mix of expert- and survey-based indicators, along the lines of their World Governance Indicators (WGI).

Any assessment of governance indicators - or any indicator for that mattermust be based on the purposes to which the indicators will be put, as Kaufmann and Kraay note. This comment examines how well the WGI and other indicators perform in two specific instances.

The first is the allocation of resources - such as the concessional aid provided by the World Bank's International Development Association (IDA) or the US Millennium Challenge Corporation (MCC)-across low-income economies. These resources are allocated according to a formula that includes, among other factors, the productivity of aid in reducing poverty in a particular country - a factor that is partly a function of the quality of governance. An indicator is thus needed that

(C) The Author 2008. Published by Oxford University Press on behalf of the International Bank for Reconstruction and Development / THE WORLD BANK. All rights reserved. For permissions, please e-mail: journals.permissions@oxfordjournals.org doi;10.1093/wbro/lkn001 Advance Access publication February 12, 2008 
measures the quality of governance across countries. By focusing on rules on the ground, using a mix of expert- and survey-based information, aggregating across indicators within a country, and providing standard errors around the means of these aggregate indicators, the WGI provide a defensible method of making cross-country comparisons. The IDA uses the judgment of World Bank experts in assessing a country's policies and institutions, but that judgment is informed by the WGI. The MCC uses five of the WGI, along with 11 other indicators, to determine a country's eligibility for its programs.

The WGI have produced some seemingly anomalous results (India, for instance, ranks in the bottom quartile worldwide on "political stability and lack of violence"). ${ }^{1}$ But aggregating across surveys in each country is needed if results are not to reflect surveys conducted across only a limited set of countries or some other bias-inducing method.

A second possible use of the WGI is to help identify the nature of the "governance problem" in a country. Bangladesh has ranked in the bottom quartile worldwide (and considerably below the low-income country average) in all but one or two of the aggregate WGI for the past decade and has been at or very near the bottom of Transparency International's corruption indicators. At the same time, the growth rate of per capita income has risen 0.1 percent every decade since the 1970 s (the growth rate is now close to 5 percent), and poverty fell 0.8 percent in five years (twice the rate in India). The country has already achieved universal primary enrollment and gender equity in secondary school, and it is on track to reduce child mortality by two-thirds (relative to 1990 levels) by 2015 .

In what sense, then, does Bangladesh have a "governance problem?" Is it possible that the data on development indicators have been mismeasured? Although some development indicators may be weaker than they appear-there is some evidence, for example, that enrollment rates among the lowest quintile of Bangladesh's population remain extremely low (World Bank 2007) - the country has clearly made tremendous gains in development over the past two decades. It is possible that it would have performed even better absent it governance problems (World Bank 2006). But, this does not answer the question of how Bangladesh's development outcomes are so much better than those of other countries with "better" governance.

One explanation is that governance indicators in Bangladesh fail to capture the fact that the country has a vibrant and active civil society that not only delivers services, but provides some accountability to government. The WGI also seem to overlook the increasingly mature media, including vernacular newspapers, which play something of a watchdog role. But these measurement errors may be second-order considerations compared with the fundamental facts that the governance indicators are capturing. Bangladesh does score in the 30th percentile on the WGI voice and accountability indicator; it comes close to the 
25 th percentile on government effectiveness. But it ranks in the 5 th percentile on control of corruption. These rankings are very low for a country that is performing so well.

Another explanation is that the relation between governance and development in Bangladesh is unique, because the Bangladeshi people have worked around the country's governance problems to spur development. When the country was born, out of a civil war, there was hardly a government. International and national nongovernmental organizations (NGOs) filled the vacuum by delivering basic services, such as health, family planning, and education, and by creating microcredit schemes. As these efforts proved effective, the government made space for these NGOs and the private sector, in some cases contributing to their financing. The government funds secondary education, for example, although 95 percent of it is provided by the nonstate sector. Similarly, Bangladesh's garment export sector grew rapidly, thanks to duty drawback systems and bonded warehouses that enabled textiles to come into the country duty-free, circumventing a highly opaque customs system.

Of course, this explanation does not explain why Bangladesh was able to work around its governance problems when so many other countries were not. Bangladesh is a densely populated, homogeneous society, in which innovations spread like wildfire. Soon after one village discovers something that works, neighboring villages find out about it and adopt it. As a result, family planning, microfinance, and other programs took off in Bangladesh more easily than they might have elsewhere. By the time the government grew strong enough to control the NGOs and others, it was too late, microfinance, family planning, and private schooling had already become commonplace. (To its credit, the government recognized this and proceeded to support the providers of essential services with finance.) The result is a country with weak governance indicators, but impressive development.

The Bangladesh case illustrates the fact that governance indicators such as the WGI do not capture the multifaceted ways in which governance affects development in a particular country. It would be dangerous to use indicators to jump to simple conclusions without understanding the specific relation between governance and development in a particular country; the indicators should certainly not be used by themselves to design policy responses to problems of weak governance.

This is the downside of having an indicator that permits intercountry comparisons of governance: the richness of country-specific detail is lost. Kaufmann and Kraay recognize this tradeoff in their concluding discussion about more disaggregated indicators. One should not go too far down this path, however, lest the main benefit of the WGI and other such indicators - their comparability across countries-be diluted in the quest for indicators that are more country specific. In 
the Tinbergen tradition of not having more objectives than instruments, one should not expect governance indicators to serve too many purposes.

\section{Notes}

Shantayanan Devarajan is the chief economist of the South Asia Region at the World Bank; his email address is sdevarajan@worldbank.org.

1. This result may not be as anomalous as it appears at first blush; however, according to the Indian prime minister, 170 of 602 districts have a significant Naxalite (Maoist) presence (Singh 2005).

\section{References}

Singh, Manmohan 2005. "PM's Reply in Rajya Sabha to the Debate on Motion of Thanks to the President's Address." March 11, New Delhi.

World Bank. 2006. Can South Asia End Poverty in a Generation? South Asia Region. Washington, D.C.

2007. To the MDGs and Beyond: Accountability and Institutional Innovation in Bangladesh. Bangladesh Development Series No. 14. Dhaka

Simon Johnson

Kaufmann and Kraay took a major step forward in thinking about governance when (together with Pablo Zoido-Lobaton) they first published their World Governance Indicators (WGI), in 1999. These indicators provided a new way to combine comparable indices along various dimensions of governance. The WGI included more countries and more pieces of data than had previously been available, complementing various other measures.

From the beginning, the WGI have clearly indicated the underlying sources of the data and how the data are constructed, explicitly reporting error bands for all estimates. This was a major innovation and remains of paramount importance.

The authors (together with Massimo Mastruzzi) have also done a great service by continuing to update the data and refine their methods. The WGI are now well established as one of the standard sets of measures that any researcher or policy analyst must consult. No measure is perfect, of course, but anyone trying to establish that a particular set of results is or is not robust is well advised to work carefully through the various vintages of the WGI. 
The appearance of the WGI coincided with a major backlash against carefully measuring and thinking hard about governance. While this backlash initially seemed rather academic and sometimes arcane, it had considerable immediate impact on both policy discussions and the impetus to research in this area. Rather than building on the WGI, serious endeavor in this area lost momentum, as three main arguments against governance indicators gained currency.

The first is that because the WGI explicitly report "errors," they cannot be relied on. This argument is completely mistaken: similar error bands should be reported for all the data used in economics, particularly for countries with weak statistical systems.

The second argument is that governance measures are not useful because many countries are growing, despite weak governance. What are the uses of these measures if they cannot predict who will and will not grow? While countries with weak institutions can, and indeed often do, grow for prolonged periods, over the longer run, it is hard to escape weak governance. Far from the exception, growth spurts are actually a standard feature almost everywhere (Berg, Ostry, and Zettelmeyer 2006) — as is the inability of many countries with weak governance to sustain the gains made during the good years.

Some countries - albeit only relatively few recently-have managed to sustain rapid growth, despite weak initial governance. Too little is known about these cases, but one common element appears to be a strong focus on exports, particularly of manufacturing goods (see Johnson, Ostry, and Subramanian 2007 for specific country examples).

These exceptions notwithstanding, if a country's governance indicators are weak-as measured by the WGI - the presumption should be that sustained growth will be difficult. Strengthening governance should help increase the odds of sustaining growth.

The third and the most interesting argument is that aggregate indicators miss a great deal of rich detail, failing to pick up the de facto arrangements that effectively take the place of more formal governance rules. Close observation of how society is organized always turns up functional forms of improvisation-that is, ways to organize transactions even where contract enforcement is weak. Some informal mechanisms may be quite efficient, in the sense that the transaction costs are not much higher than they would have been had formal contracting worked well.

Some of this organization can occur in and around the manufactured export sector. Initial improvisation could lead to more durable rules over time, both in the manufacturing sector and, through institutional spillovers, in the country as a whole.

One needs to be very careful about drawing policy implications from apparent conditions that cannot be measured; however, it is hard to make much progress 
on the basis of anecdotal evidence. Informal governance arrangements may shift and be fragile; they may also prevent people from entering new activities. The limited work on this phenomenon suggests that informal governance is often a weak substitute for well-functioning governance.

What is needed is a WGI-type approach to measure governance at a more local level, for both sectors and cities. There have already been ambitious steps in this direction [for example, Kaufmann, Leautier, and Mastruzzi (2005)], and there has been some indication that the World Bank, which is uniquely positioned in this regard, would move in this direction. So far, however, progress has been limited.

There are many good reasons to move carefully in this area, and no doubt we need to think carefully about how to make best use of resources-something that Kaufmann and Kraay reflect in this article, with their balanced assessment of alternative sources within and outside the WGI. But it would be unfortunate if the legitimate debate over interpretation of macrolevel governance measures were to undermine confidence in this area of enquiry and prevent further work from being undertaken. The field is still at an early stage. Better measures are needed to gauge what works and what does not. Such measures should stand firmly on the shoulders of the WGI.

\section{Note}

Simon Johnson is an economic counselor and director of the Research Department at the International Monetary Fund; his email address is sjohnson@imf.org.

\section{References}

Andrew Berg, Jonathan Ostry, and Jeromin Zettelmeyer. 2006. "What Makes Growth Sustained?" IMF Working Paper. International Monetary Fund, Washington, D.C.

Kaufmann, Daniel, Frannie Leautier, and Massimo Mastruzzi. 2005. "Governance and the City: An Empirical Exploration into Global Determinants of Urban Performance.” Policy Research Working Paper 3712. World Bank, Washington, D.C.

Simon Johnson, Jonathan Ostry, and Arvind Subramanian. 2007. The Prospects for Sustained Growth in Africa: Benchmarking the Constraints. NBER Working Paper 13120. Cambridge, MA: National Bureau of Economic Research. 